\title{
CONSIDERAÇÕES CLÍNICAS SÔBRE DOIS CASOS DE ANEURISMA DA AORTA ABDOMINAL
}

Pelos

Doutorando Luiz M. Bechelli E Ac. OTAVIO TISI

Os dois casos apresentados referem-se a doentes observados na, 2.a M. H., Enf. do Prof. Rubião Meira.

\section{Observação I}

Data de Entrada: 10-12-932 - Data de Saida: 10-4-933 Nome: A. N. - idade: 35 anos - Est. Civil: solteiro - Profissão: Comercio - Nacionalidade: Sirio - Domicilio: Rio Preto - Procedencia: Idem.

Queixa e duração:-Dôr pulsatil na região lombar ha 1 ano-e meio. História da moléstia atual: - $\mathrm{Ha}$ um ano e meio acordou à noite com uma queimação na face anterior da coxa esquerda e tambem nas faces lateraes Era fraca em intensidade melhorando com massagens, desaparecendo depois de uns 5 minutos. Não sabe dizer com o que peorava; nenhum fenomeno acompanhou essa dôr. No dia seguinte pôde trabalhar sem sentir nada; durante um mez e meio passou com a dôr referida, a qual conservava sempre os mesmos caracteres. Ajuntou-se por esse tempo adormecimento em todo o membro inferior, sentindo dificuldade em executar qualquer movimento. Fazia massagens ou então colocava compressas quentes sobre o membro inferior, melhorando com isso.

Depois de um mez e meio a dôr e formigamento começaram a aparecer tambem durante o dia, aumentando gradualmente o tempo de duração, até que de 10 mezes para cá essas perturbações tornaram-se contínuas. Nada fazia melhorar; só embriagando-se com aguardente conseguia isso. Peiorava com os movimentos, os quaes podia executar com alguma dificuldade.

Um mez depois de se ter iniciado a perturbação no membro inferior esquerdo começou a sentir dôr na região lombar.

Essa dôr apareceu sem nenhuma razão aparente (exercicio fisico, mau geito, queda, etc.). Era de fraca intensidade, continua, não o tendo abandonado até hoje, irradiando-se ás vezes para a direita. $O$ doente compara essa dôr a um tumor que esteja pulsando (sic). No inicio acompanhando essa dôr sentia uma pressão no peito, tendo a im- 
pressão de ter sobre ele um peso de 10 kilos. Nada fazia melhorar essa dôr, a não ser o decubito dorsal com a perna esquerda cruzada sobre a direita, fletida, melhorando muito pouco nessa posição; peiorava com o menor exercicio. Era impossivel abaixar-se para pegar qualquer objeto no chão, porque a dôr na coluna se acentuava extraordinariamente.

Essa dôr foi aumentando de intensidade, sofrendo exacerbações com os movimentos, razão porque foi obrigado a abandonar o serviço depois de 3 mezes. Tratou-se com um medico e farmaceutico tendo tomado injeçסes anti-sifiliticas (Tiozol 5 e Novasurol 20) tendo melhorado bastante. Ha 10 ou 11 mezes a dôr que se tornara branda com o tratamento acima, exacerbou-se muito, por ter andado a cavalo, dizendo que não podia apear, razão porque foi auxiliado por outra pessôa. Internou-se então na Santa Casa de Rio Preto onde fez tratamento com Aspir. Como este não desse resultado tomou 40 injeções de INa que melhorou um pouco a dôr.

$\mathrm{Ha}$ dois mezes o medico aconselhou a sua vinda para $\mathrm{S}$. Paulo, afim de fazer tratamento mais completo. Nestes dois mezes esteve com a dôr um pouco diminuida, não tendo vindo a $\mathrm{S}$. Paulo por falta de meios pecuniarios.

Os caracteres atuaes da dôr são: tem a mesma localização antiga, parecendo um tumor que pulsa, irradiando-se às vezes para a direita; desaparecu a sensação de peso no torax e continúa com a dôr e adormecimento na face antero-lateral da coxa esquerda.

Interrogatorio sobre os aparelhos: - Não tem cefaléa. Olhos, nariz e ouvidos - nada. Cardio-respiratório: não tem tosse. Sente falta de ar quando faz um ligeiro exercicio. Nega edema, dôres pre-cordiais e palpitaçóes. Aparelho digestivo: Tem bom apetite. Evacua uma vez por dia. Ap. urinario: Uriña bem. Nicturia uma ou duas vezes, mas é habito.

Antecedentes pessoais: - Trabalhava bastante; não era etilista, porem ha uns 8 mezes atraz, passou uns 15 dias tomando diariamente um a dois copos de aguardante afim de abrandar a dôr que sentia. Antes fumava um maço de cigarros por dia. Tomava 7 ou 8 chicaras de café por dia. Nega molestia na infancia. Teve lesões sifiliticas na pele sem ter lesões primarias (sic). Tratou-se com remedio que lhe fizeram desaparecer estas lesões (em 1918). Ao mesmo tempo teve gonorréa seguida de orquite.

Antecedentes hereditarios: - Pais falecidos, sendo a mãe de parto e o pai de velhice. Sua mãe não teve abortos. Tem 2 irmãos vivos e fortes. Teve uma irmã que morreu com 2 anos, ignorando a causa.

\section{Exame fisico}

Individuo tipo médiolineo. Sistema piloso muito desenvolvido. Não tem edema. Paniculo adiposo e musculos pouco desenvolvidos. Siste- 
ma osseo bem conformado; não tem esternalgia nem tibialgia. Infartamento dos ganglios cervicaes, axilares e inguinais. Posição no leito: decubito dorsal com os membros inferiores encolhidos ou se não com o membro inferior esquerdo cruzado sobre o direito fletido. Fica com as mãos nas costas para apoiar as cadeiras.

\section{Exame especial}

Cabeça : - sem pontos dolorosos. Seios da face e mastóide indolores. Facies exprimindo dôr. Olhos: conjuntivas pouco descoradas. Anisocoria: pupila esquerda um pouco maior que a direita. Reflexos pupilares a luz, à acomodação e consensual presentes. Ouvidos e Nariz: nada de anormal. Boca: Dentes com implantação e conservação má, com uma raiz infectada. Labios um pouco descorados. Lingua : recoberta por uma camada regular de saburra, tendo impressão dentaria nos seus bordos.

Pescoço: Tireoide palpavel e não aumentada de volume. Aorta palpavel na furcula, chegando superiormente até o bordo superior do esterno. Vê-se a sua pulsação na furcula esternal. As carótidas pulsam violentamente. Oliver-Cardarelli ausente.

Torax: Inspecção estatica. Face posterior: Coluna com escoliose á direita na região dorso-lombar. Cifose localisada nas $2 .^{a}$ e $3 .{ }^{a}$ lombares ; alem disso nota-se uma escoliose nessas mesmas vértebras. Face anterior: Clavicula muito saliente. Angulo de Louis não visivel. Angulo de Charpy agudo. Inspecção dinamica: Respiração impossivel de contar, porque o doente prende a respiração por causa da dôr. Fremito tóraco-vocal: normal. Pela percussão: Nas faces lateraes hipersonoridade nas bases. Pela ausculta nada.

Coração: Choque da ponta localisado no $5 .^{\circ}$ espaço intercostal esquerdo (posição deitada), um dedo para dentro da linha mamilar. Pela palpação, choque da ponta forte.

Percussão feita na posição deitada: pediculo da base um pouco alargado. Coração um pouco aumentado no seu contorno esquerdo.

Ausculta: Foco mitral: Ouve-se um sopro sistólico grave que se irradia para a face lateral, sendo audivel até a linha axilar anterior.

Ocupa a primeira bulha que é audivel e o $1.0^{\circ}$ silencio, sendo o sopro suave. A segunda bulha está normal.

Foco aórtico: Ouve-se um sopro sistólico e outro diastólico substituindo as 2 bulhas, de caracter diferente. $O$ sopro sistólico é agudo, de intensidade regular, irradiando-se para os vasos do pescoço, sendo audivel na carótida. Irradia-se tambem para baixo em direção ao apen- 
Sopro diastólico: é um pouco mais grave do que o sopro sistólico, irradiando-se tambem para cima e para baixo em direção ao apendice xifoide. Esses dois sopros tem o foco de maior intensidade no segundo intercosto direito, junto ao esterno.

Nos focos pulmonar e tricuspide ouve-se o duplo sopro irradiado do foco aortico.

Sinaes de insuficiencia aortica:

$1,{ }^{\circ}$ Choque da ponta cupuliforme +

2. ${ }^{\circ}$ Fremito de Flint -

$3.0^{\circ}$ Sopro +

$4.0^{\circ} \rightarrow$ de Flint -

5. Dansa das artérias +

6. Pulsatibilidade da aorta na furcula com duplo sopro +

7. Pulso de Corrigan +

8. ${ }^{\circ}$ Sinal de Musset +

9.0 Pulso popliteo

$100^{\circ}$ Pulso capilar de Quincke +

$11.0^{\circ} \gg$ da uvula +

$120^{\circ}$ "da lingua -

13..$^{\circ}$ Sinal de Landolfi -

$14 .^{\circ}$ » de Alvarenga - Durosier +

15..$^{\circ}$ Dopelton de Traube +

$16 .^{\circ}$ Pistol shot na pediosa -

Arterias radiais de paredes um tanto endurecidas; as temporais são sinuosas e regularmente visiveis, sendo um pouco duras. Os dois pulsos parecem ser isócronos. Pulso 96.

P. Art. $($ Tycos $)=14-7$

Abdomen: Inspecção: Nota-se um tumor acima do umbigo. Esse tumor é pulsatil, notando-se bem este fenomeno quando se olha tangencialmente. Inferiormente essa pulsação não ultrapassa 0 umbigo, chegando superiormente até o apendice xifoide. Lateralmente essa pulsação extende-se até um dedo transverso para dentro da linha mamilar. O tumor tem um diametro transversal de $12 \mathrm{cms}$. e longitudinal de $11 \mathrm{cms}$.

A pulsação é sincronica com a sistole cardiaca, sendo, mais forte no lado esquerdo que no direito. Nota-se contração peristaltica em cima do tumor, indo do lado esquerdo para o direito.

Palpação: palpa-se um tumor na região do epigastrio, a direita e a esqerda da linha mediana, mal delimitado, porquanto dá impressão que seus bordos penetram profundamente. Superficie lisa em toda a sua extensão. Pela palpação sente-se pulsação intensa. Sente-se um fremito no contorno direito do tumor, ha uns 3 dedos transversaes do re- 
bordo costal. Sente-se sobre o tumor um cordão um tanto duro, ás vezes gargarejante (Quinche); pela inspeção viu-se que tinha contração peristaltica; não se consegue delimitar para fòra do tumor o cordåo que palpamos sobre o mesmo. $O$ tumor é imovel respiratòriamente, mesmo nos decubitos.

Pela palpação sente-se expansibilidade do tumor, palpando-se nos 3 sentidos.

Ausculta: Ouve-se permanentemente um sopro sistólico. $O$ ponto de maior audibilidade é o mesmo em que se sente o fremito.

Pela ausculta na região lombar não se ouvia sopro. Ouvia-se uma bulha sistólica de pequena intensidade.

Palpa-se o cólon transverso em todo o seu trajeto de flexura à flexura.

Cecum e sigmoide, palpaveis, não dolorosos. Psoas esquerdo e direito dolorosos. Logo abaixo do rebordo costal, correndo sobre o tumor, palpa-se o bordo inferior do figado que não é doloroso.

Palpa-se o rim direito ptosado, pouco doloroso e imovel. Não se palpa o rim esquerdo. Não se consegue estabelecer relação entre $o$ tumor e o rim. Palpa-se o baço logo abaixo do rebordo, duro e cortante.

$\mathrm{Na}$ região lombar esquerda sente-se uma pulsação intensa tomando o angulo costo-muscular, sentindo-se até o flanco na linha axilar posterior. Dôr intensa nas segunda e terceira lombares, que são as que constituem principalmente a cifose. Ainda pela inspeção nota-se que a região lombar esquerda está proeminente e apresenta uma pulsaçã́o sistólica evidente. Nessa régião ouve-se uma bulha sistólica de pequena intensidade.

Coluna absolutamente imovel; as primeira, segunda e terceira lombares apresentam um desvio cifo-escoliótico direito. Pela palpação não se percebe retardo do pulso crural em relação ao radial.

Exame do sistema nervoso: - Reflexos tendinosos (patelar, aquiliano, radial, tricipital, e bicipital) presentes, assim como os reflexos cutaneos (abdominaes e cremasterino)

Babinski e Romberg ausentes.

Sensibilidades térmica, tactil e dolorosa diminuidas nas faces anterolateraes da coxa esquerda.

\section{SENSIBILIDADE PROFUNDA}

$10^{\circ}$ - pela movimentação do grande artelho; integra nos 2 lados.

$2 .^{\circ}$ - sensibilidade barestésica : integra.

$3^{\circ}$ - sensibilidade dos troncos nervosos; a pressão sobre o ciatico esq. no seu trajeto na coxa, determina formigamento e dormencia só na coxa. Lasegue: negativo.

$4 .^{\circ}$ - sentido muscular : a sensação da posição no espaço está integra nos 2 lados. Diz mais ou menos a que distancia fica o 
Revista de Medicina

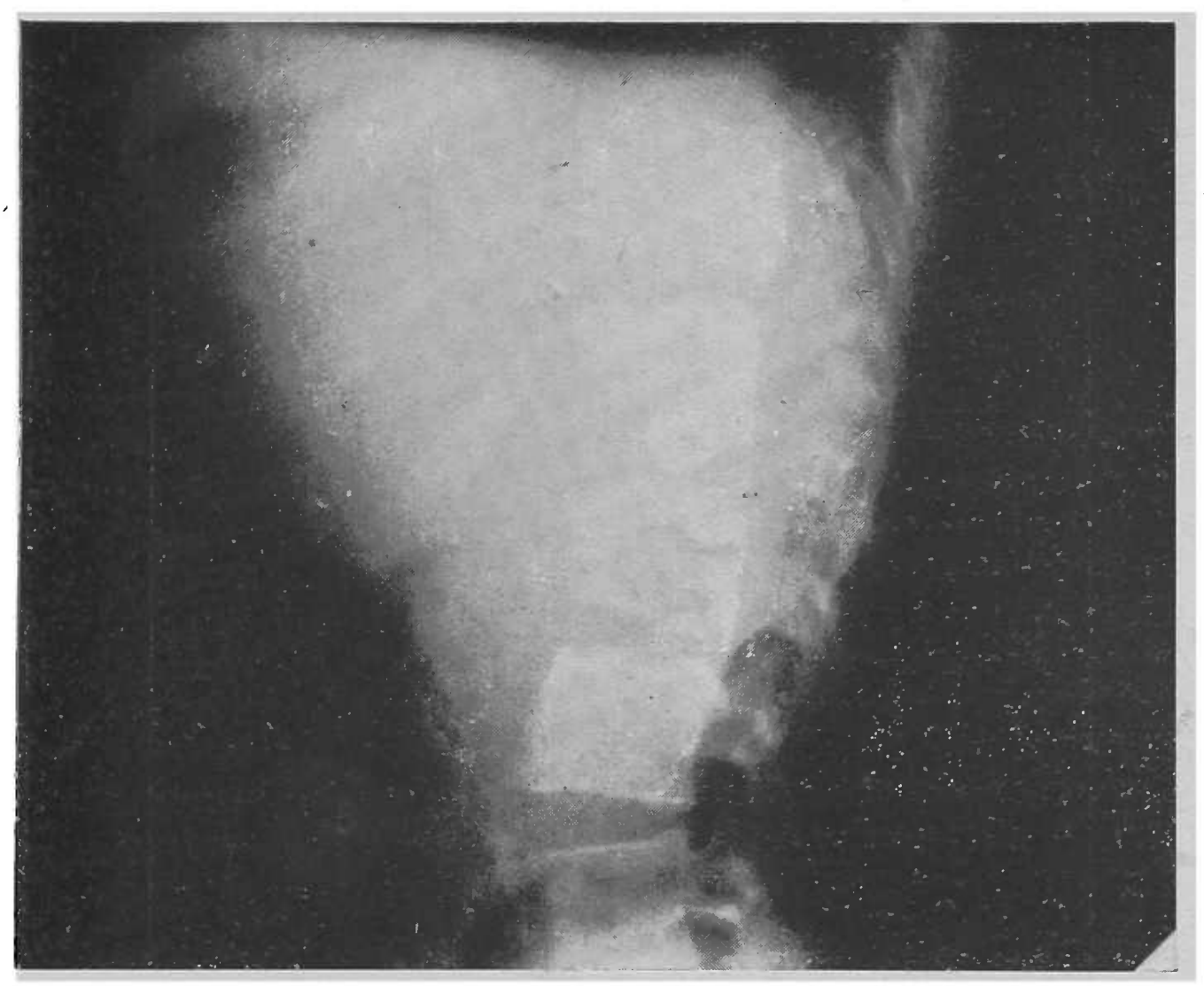

Observação I 
Revista de Medicina

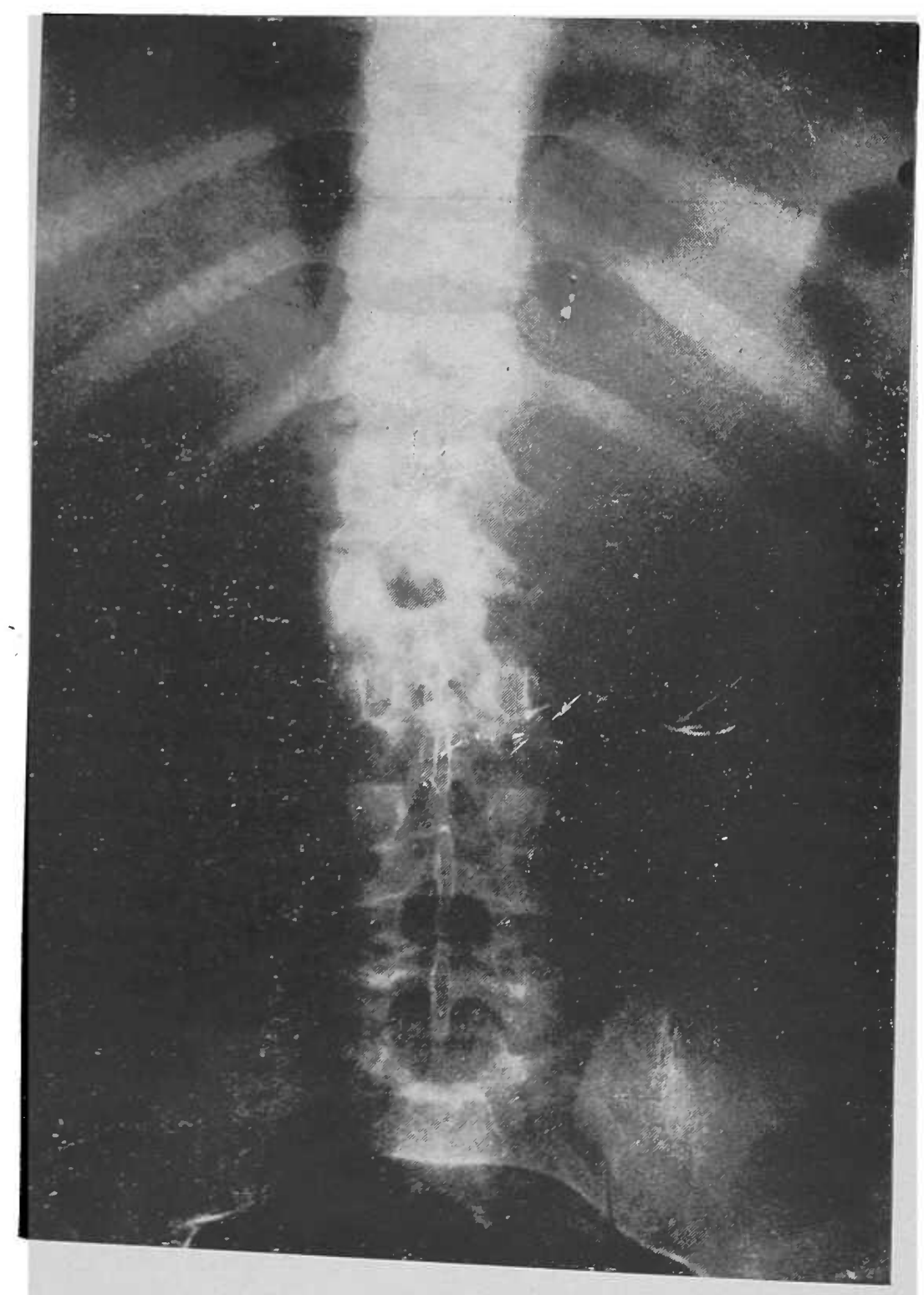

Observação I 
Revista de Medicina

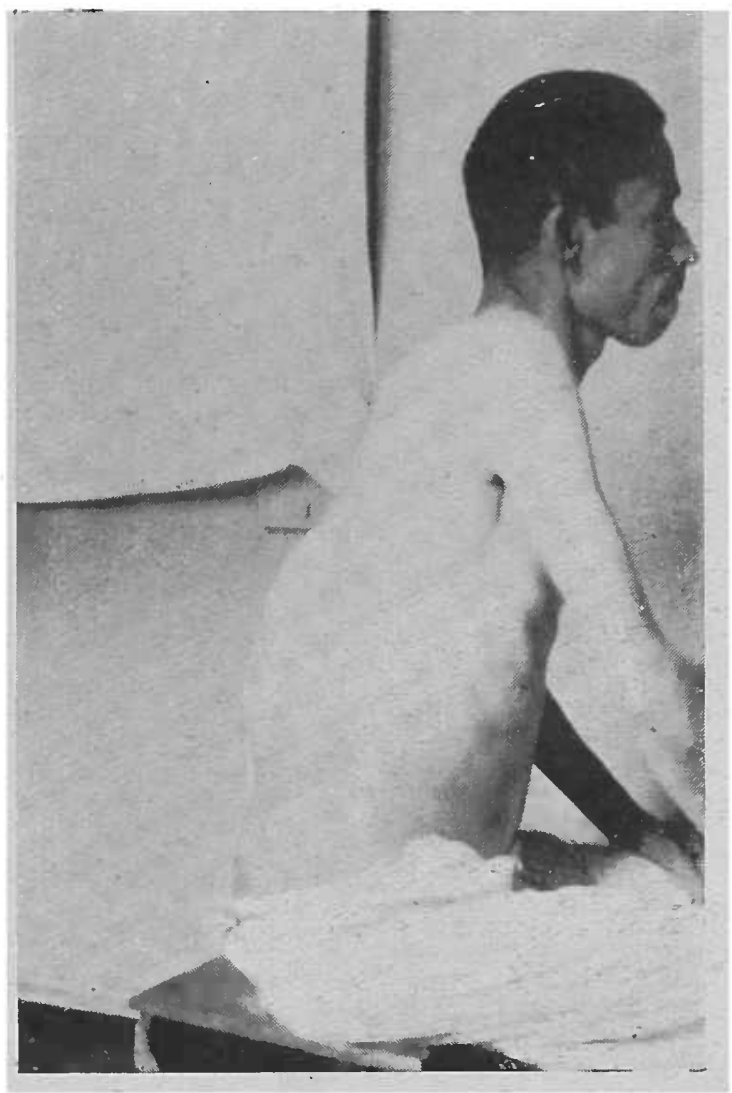

Observação II 

pé levantado da cama e com outro membro é capaz de reproduzir o movimento.

EXAME DA MOTILIDADE

Tonus muscular: $O$ tonus muscular está normal.

Força muscular : normal nos membros inferiores.

\section{EXAMES DE LABORATÓRIO}

Wassermann: ++++

Exame de urina: Dens. 1020. Alb.: traços leves. Glicose : - Sed.: Raros leucócitos. Algums hematías. Urato amorfo e raros cristais de oxalato.

Eletrocardiograma: preponderancia esquerda.

Radiografia da coluna lombar: (14-12-32).

Erosão da porção anterior do corpo das $1 .{ }^{a}$ e $2 .^{\text {a }}$ vertebras lombares com destruição quasi completa da $3 .^{a}$; espaço articular conservado:

Pequeno osteofito na porção anterior e superior do corpo da $5 .^{a}$ lombar. (Sinais radiológicos de aneurisma abdominal com atrofia por compressão das 1.a, 2.a e 3.a vertebras lombares).

Radiografia do coração e aorta descendente: (10-3-33)

Aumento da area cardiaca; hipertrofia das cavidades direitas e ventriculo esquerdo.

Aorta alongada e sinuosa. Aortite cronica. (Dr. C. Campos).

Dosagem de uréa: $0,57 \%$.

Prova d'agua : Em 2,30 horas eliminou $1.441 \mathrm{cc}$. de urina tendo a densidade chegado a 1.000 .

Administração do liquido ( 1.500 cc. de agua), das 8,30 ás 8,45 .

$\begin{array}{rrc}\text { Hora } & \text { Quantidade } & \text { Densidade } \\ 9,15 & 140 \text { cc. } & 1.002 \\ 9,45 & 400 \text { cc. } & 1.000 \\ 10,15 & 420 \text { cc. } & 1.000 \\ 10,45 & 390 \text { cc. } & 1.002 \\ 11,15 & 46 \text { cc. } & 1.010 \\ 11,45 & 45 \text { cc. } & 1.012\end{array}$

Prova de cóncentração: não foi feita, pois a densidade que tomamos de uma urina era de 1.026.

Diagnóstico: - Aneurisma da aorta abdominal. Insuficiencia aortica. Sifilis. 


\section{Cbservação II}

A. N., solt., brasileiro, 35 anos de idade, vendedor ambulante.

Data de entrada - 2-1-933. Proc. : Mogí das Cruzes.

8 mezes.

Queixa e duração - Dôr na região lombar e virilha esquerda, ha

História da moléstia atual - $\mathrm{Ha} 8$ mezes, amanheceu um dia com dôres fracas, na região lombar. A dôr era contínua, fraca, latejada quando em repouso, de pontada quando fazia movimentos. Não tinha irradiação. Não foi precedida nem acompanhada por nenhum outro fenomeno. A intensidade da dôr aumentava quando fazia movimentos com o corpo, quando tossia, emfim sempre que fazia esforços. Como no inicio a dôr não o ineomodasse demasiado continuou a trabalhar.

A posição que abrandava a inténsidade da dôr, era o decubito lateral esquerdo incompleto, com o corpo em arco, com a concavidade voltada para a esquerda. Não cessando a dôr, tomou uns remedios (não sabendo informar quaes foram), sentindo um certo alivio.

Ha 6 mezes a dôr irradiou-se para a virilha esquerda, sendo os caracteres da dôr semelhantes aos da região lombar.

A intensidade da dôr, que até essa ocasião era fraca, começou a aumentar e ha 4 mezes foi obrigado a abandonar o trabalho, mesmo porque sentia "dureza" na virilha, que entravavam as pernas.

Ha 3 mezes entrou para esta Enfermaria donde saiu depois de 2 mezes; mas 15 dias após ter sahido voltou novamente por se lhe terem exacerbado as dôres, que se tinham abrandado durante sua estadia nesta enfermaria.

Antecedentes pessoais - nada refere digno de nota.

Antecedentes famil. e hered. : - nada refere.

Interrogatório dos differentes aparelhos. - não foi apurado dado de valia.

Exame fisico - Individuo de tipo longilineo, emagrecido, musculos pouco desenvolvidos. Decubito lateral esquerdo incompleto. Marcha : pende o corpo para a esquerda.

A percurssão ligeira da coluna vertebral é indolor. É dolorosa a percussão do flanco esquerdo. Mucosas visiveis ligeiramente descoradas. Ganglios epitrocleanos e inguinaes palpaveis duros e indolores.

Artéria radial ritmica, isócrona, depressivel, pulsando 114 vezes por minuto. Nå foi notado retardo entre a pulsação da radial e da
femural. Exame especial - Notaremos nesta parte sòmente o que de mais
importante foi observado.

Abdomen - À inspecção nota-se uma pulsação situada no terço tindo-se até a região lombar parte superior. A palpação sente-se um 
Revista de Medicina

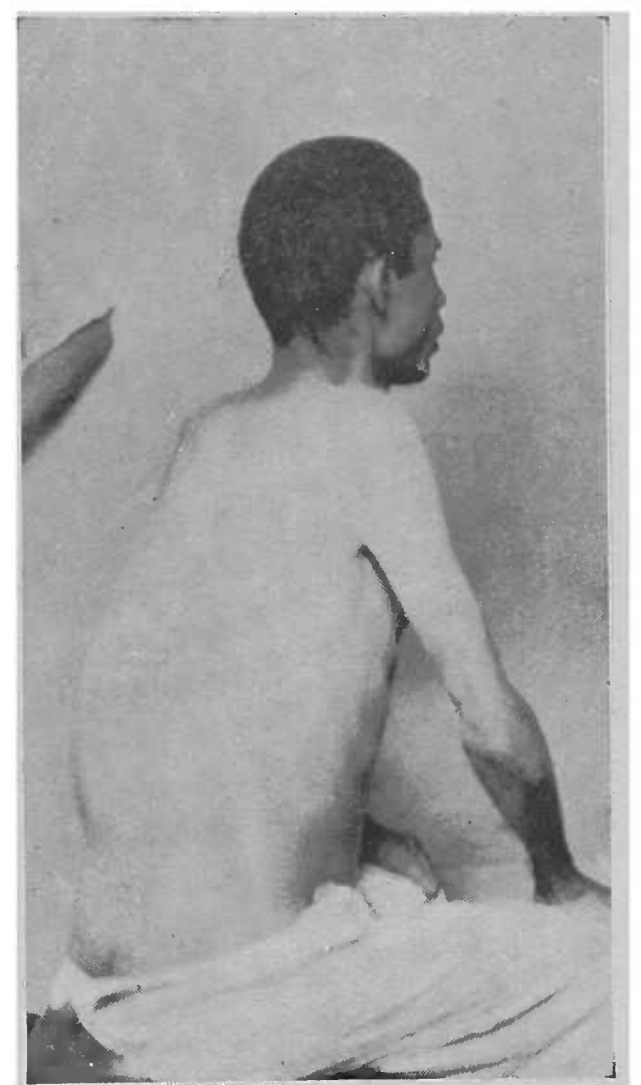

Observação II 
Revista de Medicina

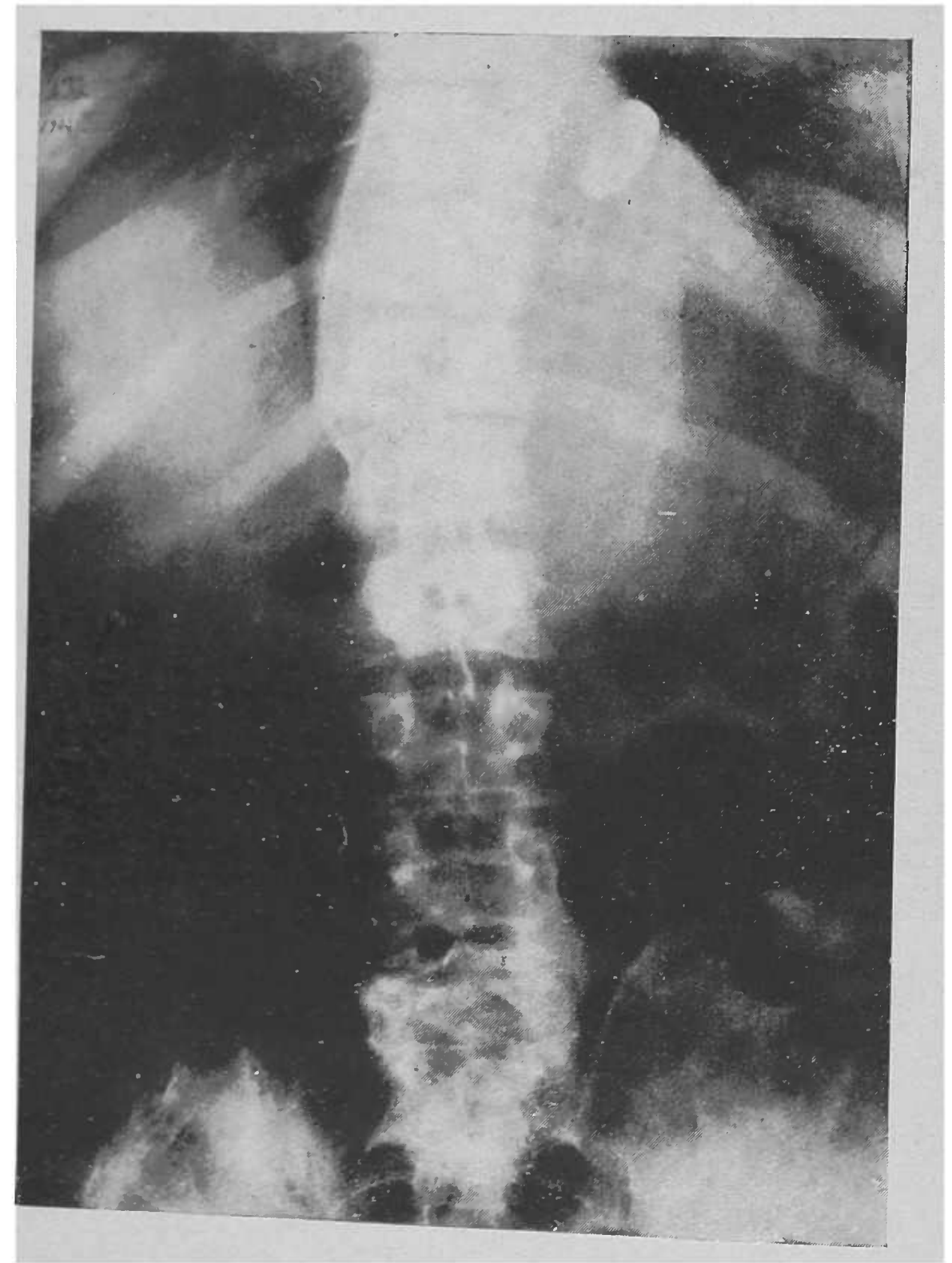

Observação II 
tumor de paredes lisas, de consistencia elastica, pulsatil, espansivo, ligeiramente doloroso à palpação leve. $\mathrm{Na}$ região epigastrica sente-se um fremito sistolico, não muito intenso, localisado. $O$ tumor não é movel com os movimentos respiratórios, nem manualmente.

A mão colocada sobre o tumor sente uma pulsação, sincronica com o choque da ponta. A area ocupada pelo tumor é delimitada pelas seguintes linhas: inferiormente, uma linha de concavidade superior, como que abraçando o apendice xifoido, e distante dele cerca de 4 cents.; esta linha continua margeando o rebordo costal esquerdo e fica distante dele cerca de 4 cents. Para cima o tumor junta-se ao rebordo costal, não sendo possivel perceber o limite pela palpação. $\mathrm{Na}$ altura da linha axilar anterior e distante do rebodo costal cerca de 12 cents., o tumor apresenta uma chanfradura, e em seguida uma concavidade para a esquerda continuando-se por uma linha reta para a região lombar até a coluna vertebral. $O$ bordo posterior do tumor encosta-se à coluna vertebral.

A ausculta, ouve-se na região epigastrica um sopro sistolico, sem propagação; e no restante uma bulha sistólica.

Exames de laboratório:

R. de Wassermann: ++++

Electrocardiograma - normal

Exame de urina - normal

Dosagem da uréa no sôro - $(15-3-33)-0,50$ grs. \%o.

Radiografia da coluna dorso-lombar - (3-1-33) Corrosão da parte anterior do corpo da 1:a vertebra lombar, XI e XII dorsais. Escoliose com o angulo ao nivel da. XII V. D. Sinais de ectasia da aorta abdominal em sua primeira porção. (a) Dr. Eduardo Cotrim.

Díagnóstico : aneurisma da aorta, abdominal - sifilis.

Considerando as anamneses fornecidas pelos pacientes, dois fatos resaltam imediatamente : a dôr na região lombar e a sua irradiação para a coxa, de intensidade crescente com o progredir da molestia. Com efeito, no caso I tinhamos formigamento e dộ nas faces lateraes e anterior da coxa esquerda; no caso II dôr na região inguinal e coxa esquerda. A face anterior da coxa é inervada pelos filetes sensitivos do nervo genito-crural e crural; as faces externa e a interna são inervadas respetivamente pelo femuro-cutaneo e obturador. Quanto à região inguinal, recebe os seus filetes dos nervos abdómino-genitaes. Pois bem, todos esses nervos originam-se do plexo lombar e uma nevralgia dos mesmos deve ser relacionada a uma compressão por um tumor com séde na região lombar esquerda, pois os fenomenos passam-se nesse lado. Os pacientes queixam-se de dôr na região lombar, que eles comparam a uma dôr pulsatil, incomodando-os continuamen- 
te e sem fases de acalmía : quando existe uma dôr intensa, duradoura, tanto na região dorsal como lombar, que não cede a nenhum medicamento, devemos ficar de sobreaviso, pois essa dôr pode ser a expressão de uma compressão, e a compressão é mais frequentemente exercida por um aneurisma. Pela anamnese podiamos pois suspeitar da existencia de um aneurisma.

$O$ exame fisico revelou o seguinte: no caso II palpa-se da regiáo epigastrica até a região lombar um tumor pulsatil, com expansibilidade, fremito, ouvindo-se um sopro sistólico e bulha sistólica. No caso I encontramos os mesmos sinaes, porem limitados somente á regiáo epigastrica e região lombar, na qual a lordóse habitual fora substituida por uma cifo-escoliose.

Com esse quadro impóe-se o diagnóstico de aneurisma. Contudo na pratica os aneurismas não se apresentam com fenomenologia e sinaes propedêuticos tão evidentes como nos casos apresentados. Ha casos em que esse diagnostico oscila entre o aneurisma e outras afecções e justamente sobre esse diagnóstico diferencial vamos nos deter.

Assim, considerando as pulsações epigastricas, são frequentes os erros de diagnóstico, podendo-se considerar aneurismatico um individuo com pulsações nervosas da aorta ou com uma arterioesclerose. Mesmo Laennec incidiu nesse erro, diagnosticando aneurisma em um doente que apresentava pulsações epigastricas post-febrís, pulsações essas que desapareceram pouco tempo depois.

As pulsações epigastricas podem ser:

$1 .^{\circ}$ neuropaticas

$2 .^{\circ}$ transmitidas por tumores em contato com a aorta

$3 .{ }^{\circ}$ por arterioesclerose aortica deformante

4. ${ }^{\circ}$ por aneurisma

As pulsações neuropatičas são comuns nas jovens histéricas, nos moços neuropaticos especialmente sofrendo de gastropatias; reconhecem-se essas pulsações seja pela idade em que se apresentam, seja pelas condiçסes neuropaticas dos individuos atingidos, bem como pela transitoriedade e mutabilidade da pulsação.

Segundo Luton são pulsações violentas que se constatam em certos individuos no trajeto da aorta abdominal, sem que existam lesões materiaes do vaso. Geralmente é o proprio doente que nota esses batimentos, procurando o medico: este entấo, pela inspecção e pela palpação constata no epigastrio ou mais abaixo os batimentos em questão; em taes casos pode o individuo sentir dôr e o médico, ouvindo um sopro, fica extraordinariamente embaraçado no seu diagnóstico: isso porque a artéria pulsando exageradamente, basta a mais leve pressão para que se tenha a formação de turbilhões e portanto do sopro. Nesses casos o observação mostra que a pulsação epigastrica, 
batimentos sobrevêm por periodos; eles podem durar mezes, aparecer bruscamente e curar-se da mesma maneira.

O diagnóstico diferencial do aneurisma com os tumores que repousam sobre a aorta e transmitem a pulsação desta, tem a mesma importancia, porque diagnosticando-se um tumor retro-peritoneal pode-se tentar a operação, e sendo um aneurisma o prognóstico muda. Esse diagnóstiço diferencial é dificil sob o ponto de vista clinico, prescindindo-se do auxilio da radiografia. Cardarelli em uma de suas lições sobre aneurisma, nos ensina os critérios que devemos seguir: "Existem, diz ele, certos criterios falhos. Por exemplo o criterio do pulso: se o pulso das artérias situadas abaixo da tumefação pulsatil é pequeno e retardado, então teremos o aneurisma; se não está modificado então é tumor. Isso porem não é verdade, porque um tumor que faz pressão sobre a aorta pode produzir um certo retardo nas artérias que estão abaixo; portanto esse criterio do pulso não tem nenhuma importancia.

Outro critério consiste em explorar a pulsação na posição genupeitoral: se ela desaparece quer dizer que o tumor repousava sobre a artéria; se não se modifica é um aneurisma. Isso não é exato, pois se o tumor está em relação com a artéria com esta contrae aderencias, isto é, forma um todo unico, que não se modifica com as mudanças de posição; esse critério só terá valor no caso em que cessam as pulsações, mas se estas continuam nada se póde deduzir.

Os critérios mais positivos aos quaes devemos recorrer são os seguintes: primeiramente é a pulsação expansiva, que se verifica em todos os sentidos, de cima para baixo, lateralmente e de traz para frente. Essa pulsação em todos os sentidos somente um aneurisma pode apresental-a; o tumor dá uma pulsação que se propag̀a em um unico sentido. Um segundo critério é a qualidade da pulsação, critério esse percebido quando se tem uma certa pratica de palpação; consiste em se distinguir a pulsação do aneurisma daquela que se percebe com os tumores. A pulsação do aneurisma é lenta, expansiva; quanto mais se faz pressão com os dedos melhor se percebe a expansão da pulsação. A pulsação comunicada, como no caso dos tumores, assemelhase a um levantamento. Este meio propedeutico é falho quando se trata de coleções liquidas, em que a pulsação é expansiva porque é recolhida por uma massa liquida. Quando o tumor é solido a pulsação é limitada, não expansiva.

Finalmente temos um terceiro critério, que considero o mais positivo: quando se exerce uma forte pressão sobre $o$ tumor, desaparece a pulsação sob os dedos, e depois tambem a pulsação das arterias femuraes. $\mathrm{Na}$ aorta dilatada não se consegue facilmente suprimir a pulsação, justamente porque è dificil exercer uma compressão completa».

Entre os tumores do epigastrio podemos encontrar sarcomas que são pulsateis por si ; apresentam ainda expansibilidade identica à dos 
aneurismas. A diferenciação nestes casos é bastante dificil, mas devemos ter presente que sómente os grandes sarcomas apresentam a expansibilidade; de outro lado quanto maior fôr o aneurisma menos nitidos serão os seus sinaes. Esse diagnostico diferencial é facilitado pelos outros fenomenos que sóem acompanhar os tumores.

Quanto às pulsações epigastricas por arterioesclerose aortica deformante, podem ser confundidas com as pulsações do aneurisma da aorta abdominal. $\mathrm{Na}$ arterioesclerose as artérias tornam-se mais superficiaes e mais longas: a aorta abdominal esclerosada, não podendo extender-se em linha réta, deforma-se e constitue uma curva de concavidade para a coluna vertebral e com a convexidade para a direita e anteriormente, conseguindo-se frequentemente palpal-a como um cordão duro. Nesses casos os individuos apresentam arterioesclerose das temporais e humerais. Falta em geral o sintoma mais importante para o diagnostico de aneurisma, a dôr. Para Cardarelli a ausencia da dôr faz perigar o diagnóstico de aneurisma. Contudo, nos processos pronunciados de arterioesclerose abdominal pode existir a dôr, que é a expressão da pulsação exagerada da artéria. $\mathrm{Na}$ arterio esclerose ha impressão de uma pulsação rapida; no aneurisma a pulsação é lenta e expansiva.

A medida que falamos no valor das pulsações epigastricas, deixamos entrever em que condiçóes elas concorriam para o diagnóstico de aneurisma. Nos dois casos apresentados vimos a serie de fenomenos que nos levaram ao diagnóstico de aneurisma, não sendo necessario voltarmos a eles. Diremos apenas algumas palavras sobre o sopro sistólico, que se ouve à ausculta da região onde tem séde o aneurisma, sinal esse que é levado em muita consideração por alguns semiologistas. Aplicando-se o estetoscópio diretamente sobre a aorta, sempre se exerce uma certa compressão ; esta, embora muito leve, deter. minará uma interrupção da corrente e portanto um sopro, independente da existencia de um aneurisma. O estetoscópio deve ser aplicado sobre um ponto no qual não é possivel exercer pressão sobre a arteria pulsatil, por exemplo sobre o arco costal, em correspondencia do nivel da pulsação. Neste caso a ausculta do sopro tem valor.

Quanto ao fremito, não sendo senão a sensação tactil do sopro, a leve pressão que determina este ultimo, vae gerar tambem um fremito. O Prof. Almeida Prado, em seu recente artigo sobre aneurismas, cita um caso no qual sentia-se um fremito sistólico pela palpação da aorta abdominal, fremito esse sòmente perceptivel pelos dedos que ficavam ajusante do ponto em que a ação compressora manual mais se fazia sentir. A radiografia mostrou tratar-se de uma ectasia simples
da aorta.

A corrosão dos corpos vertebraes é elemento de valía no diagnostico; essa corrosão pode ser vista nos dois cascs. 
Feito o diagnóstico de aneurisma precisamos fazer o

\section{DIAGNÓSTICO DA SÉDE}

Diagnostica-se a séde de um aneurisma pelos fenomenos de compressão e pelo ponto do abdomen em que a reconhece a exploração fisica. Podemos considerar como séde do aneurisma as seguintes artérias :

1. tronco celiaco

2. ramos do tronco celiaco: hepatica, esplenica e coronaria estomaquica.

3. mesentérica superior

4. renal esquerda

5. aorta abdominal, porção sub-diafragmatica.

O aneurisma do tronco celiaco é extremamente raro; encontra-se atraz do lobo hepatico esquerdo, mas devido à sua forma esférica pode tornar-se muito superficial e nitidamente delimitavel por meio dos dedos. Contrariamente ao aneurisma da aorta abdominal, ele apresentaria um certo grau de deslocabilidade respiratoria.

Quanto aos aneurismas dos ramos do tronco celiaco, podemos afastar a séde na arteria hepatica, pois localisam-se a direita, levantando - figado, geralmente dando ictericia e ascite. Os aneurismas da esplenica são raros e simulam um tumor do baço, podendo produzir dốr no hipocondrio esquerdo. Os aneurismas da coronaria estomaquica determinam gastralgias relacionando-se ou não com os alimentos; simulam tumores do estomago, localisados na pequena curvatura.

Os aneurismas da artéria mesentérica superior são excessivamente raros; localisam-se geralmente na região umbilical; tem o caracteristico de serem extremamente moveis, podendo-se deslocar seja para a direita como para a esquerda.

Os aneurismas da arteria renal são igualmente raros. Produzem uma lombalgia cronica contínua; ha hematuria que se manifesta por acéssos e perturbação da função renal. As vezes o aneurisma é palpavel na região lombar. O diagnóstico é possivel quando se trata de um tumor pulsatil, que apareceu em seguida a um traumatismo acompanhado de hematuria.

Os aneurismas da aorta abdominal fazendo proeminencia no epigastrio, tem a sua séde geralmente entre o tronco celiaco, arteria renal $e$ mesentérica superior. Caracterisam-se pela grande variedade de fenomenos dolorosos, o que se explica pelo numero consideravel de elementos nervosos contiguos à região e que podem sofrer a compressão pelo saco aneurismatico. Um dos fenomenos dolorosos mais encontrados é a nevralgia lombo-abdominal, contínua ou por acessos, podendo se irradiar aos flancos, às fossas iliacas, ao escroto, perineo e membros inferiores. Essas reações dolorosas tem uma evolução progressiva, sem 
periodos de acalmía. Para o lado dos orgãos podemos ter sintomatologia dolorosa simulando as cólicas renaes e hepaticas, afecções gastralgicas intensas e sindromes intestinaes dolorosos com descargas diarreicas. Exerce compressão nas vértebras corroendo-as, podendo ulteriormente chegar a comprimir a medula. Ao exame fisico notase muitas vezes um tumor pulsatil, tendo como séde a região epigastrica, dependendo a sua exteriorisação do tamanho do saco aneurismatico.

Acabamos de ver a sintomatologia do aneurisma da aorta abdominal logo abaixo do diafragma e tambem dos aneurismas que dela se originam. Os aneurismas do tronco celiaco, dos seus ramos e da mesentérica são eliminados do diagnóstico, pois os seus sintomas não se encaixam no quadro clinico apresentados pelos nossos doentes. Ficam de pé, para o diagnóstico, os aneurismas da artéria renal esquerda e da aorta abdominal: tanto um como outro determinam lombalgias e são susceptiveis de serem percebidas na parede anterior do abdomen, sem perder o contato com a região lombar. Contra a hipótese de aneurisma da renal temos a ausencia de perturbações da função renal. A favor do diagnóstico de aneurisma da aorta abdominal, temos no caso I um tumor pulsatil palpavel no epigastrio e avançando a esquerda e a direita da linha mediana: para Cardarelli esse fato indica aneurisma da aorta, logo após a sua saída do diafragma. No caso II, em que havia um tumor pulsatil que era palpavel desde o epigastrio até a região lombar, contornando o hipocondrio esquerdo, o diagnóstico de aneurisma da aorta tambem se impбe, sobretudo devido ao tamanho do saco aneurismatico. Esse fator, tamanho de aneurisma, é de importancia no diagnóstico: o Prof. Miguel Couto cita um caso em que existia um enorme saco aneurismatico, que estava colocado no hemiabdomen direito. Apezar de numerosos dados a favor de aneurisma da artéria renal, decidiu-se a favor da localisação aórtica sòmente devido às dimensōes do aneurisma, diagnóstico esse que foi confirmado posteriormente pela autopsia.

\section{EVOLUÇÃO E RUTURA}

O aneurisma tem um crescimento contínuo, esse crescimento podendo se fazer ininteruptamente ou por etapas. Quanto menor é a artéria e mais longo o tracto dilatado, tanto mais longamente as condições do aneurisma permanécem invariaveis. Nos aneurismas sacciformes as condiçōes são mais desfavoraveis, especialmente naqueles com um cólo largo, atravéz do qual pode penetrar uma forte torrente sanguinea e exercer a sua ação dilatadora. Esses aneurismas tem uma evolução progressiva e são sujeitos tanto mais facilmente à rutura quanto menor é o seu volume.

Nos casos apresentados observamos as seguintes evoluções: 


\section{EVOLUÇÃo DO CASO 1}

Do dia 10-12-32 até 28-12-32 tem passado como antes da entrada nesta Enfermaria. Tem tomado injeçóes diarias de lodeto de Sodio na veia e Hidróxido Bismuto duas vezes por semana. A unica melhora que sentiu foi uma diminuição pequena da dôr na região lombar esquerda.

Sopro sistólico na região lombar.

Dia 28-12-32: Começou a sentir dôr na região lombar direita : essa dôr antes aparecia como irradiação da dôr que sentia na região lombar esquerda ; agora tornou-se constante. Tem os mesmos caracteres da dôr na região lombar esquerda, isto é parece um tumor que pulsa.

Dia 31-12-32: Continua com a dôr na região lombar dir., a qual o tem incomodado dia e noite. Tanto essa dôr como a da região lombar esquerda são mais intensas à noite.

Quasi todas as noites o doente toma injeção de Pantopon para dormir.

Dia 11-2-33: O doente tomou 42 injeções de INa e 8 inj. de $\mathrm{Hi}$ dróxido Bismuto (estas foram prescritas 3 vezes por semana). Desde o dia 15 de Janeiro, a medida que ia tomando as injeções, começaram a melhorar as dôres nas regióes lombares direita e esquerda, tanto que atualmente essas dôres são muito leves. Pode dormir regularmente à noite, dispensando desde dia 15 de Janeiro o uso de Pantopon, coisa que lhe era impossivel antes.

Dia 22-2-33: Continua melhorando das dôres nas regiões lombares. $\mathrm{O}$ doente tomou até hoje 12 inj. de Hidróxido de Bis. e de lodeto de Sodio 52 inj.

Hontem iniciou o tratamento brasileiro para aneurisma, com o Dr Livramento (aplicações de correntes galvanicas).

O esquecimento na coxa esquerda está um pouco melhorado.

Dia 9-3-33: A dor na região lombar está muito melhorada: acha que melhorou 70 a $80 \%$ em relação ao que estava antigamente. $O$ esquecimento da coxa esquerda está mais ou menos o mesmo.

Tomou 66 inj. de INa e 18 de Hidróxido de Bismuto ; 7 aplicações de correntes galvanicas.

Dia 10-4-33 : Continua na mesma quanto ás dôres, isto é muitissimo melhorado (ver dia 9-3-33).

Tem esquecimento na coxa esquerda, mas só depois de andar um pouco.

Tomou 89 injeções de lodeto de Sodio e 31 injeções de Bismuto (hidroxido).

Foram-lhe feitas 16 aplicações do tratamento brasileiro de aneurisma (correntes galvanicas). 


\section{EVOLUÇÃO DO CASO II}

Dia 15-1-33: Aumento da area pulsatil. 18-1-33 - Continúa o aumento da area pulsatil. As dôres tem aumentado de intensidade. (Fotos. 3-4-5)

Dia 1-3-33: Continua o aumento da area pulsatil. $\mathrm{O}$ tumor já faz saliencia na região lombar (v. fot.) Quando palpavamos o tumor 0 paciente dizia que não sentia que nós o estavamos palpando. Pesquizada a sensibilidade térmica, tactil e dolorosa, constatamos ausencia dessas sensibilidades na região lombar esquerda e nas faces anterior e externa da coxa esquerda.

Constatamos tambem a atrofia de todo o membro inferior esquerdo, e edema da face dorsal do pé esquerdo.

Por essa ocasião o paciente já não podia ficar no leito na posição que foi descrita no inicio. A posição é agora o decubito lateral direito incompleto.

Dia 15-3-33 - Amanheceu com febre e delirante.

- 16.3.33 - Desaparecimento da febre e do delirio.

- 20-3-33 - Exitus ás 10 horas da manhã.

Nesse mesmo dia foi feita a necrópsia.

Nome: A. N. - Idade : 37 anos - Dia do óbito: 20-3-33 (10 hs) - Dia da necropsia : 20-3-33(15,40 hs) - Necropsiante : Dr. C. Mignone - $\mathrm{N}^{\circ}$ da necropsia : SS-3104/33 - Raça : branca Sexo: masculino -- Nacionalidade: brasileira - Clinica : 2.a M. H. (Santa Casa)

\section{RELATÓRIO DA NECRÓPSIA}

Generalidades: Cadaver de adulto do sexo masculino, côr branca, medindo 162 cms. de comprimento.

Cabeça simetrica, revestida por cabelos curtos e negros. Palpebras semi-cerradas. Córneas brilhantes, pupilas igualmente dilatadas. Nariz, bôca e ouvidos nada mostram de particular. Dentes cariados e mal conservados. Pescoço fino e cilindrico. Torax mesoestenico, simétrico, mostrando os espaços intercostaes ligeiramente deprimidos. Abdomen ligeiramente abaulado; na região lateral esquerda do abdómen nota-se externamente um abaulamento mais evidente na sua parte posterior. Genitaes externos e anus nada digno de nota. Rigidez cadavérica ausente.

Cabeça: Cranio bem conformado. Paredes ósseas finas e resistentes. Dura-mater de aspeto normal.

Encéfalo: Peso 1400 grs. 


\section{Revista de Medicina}

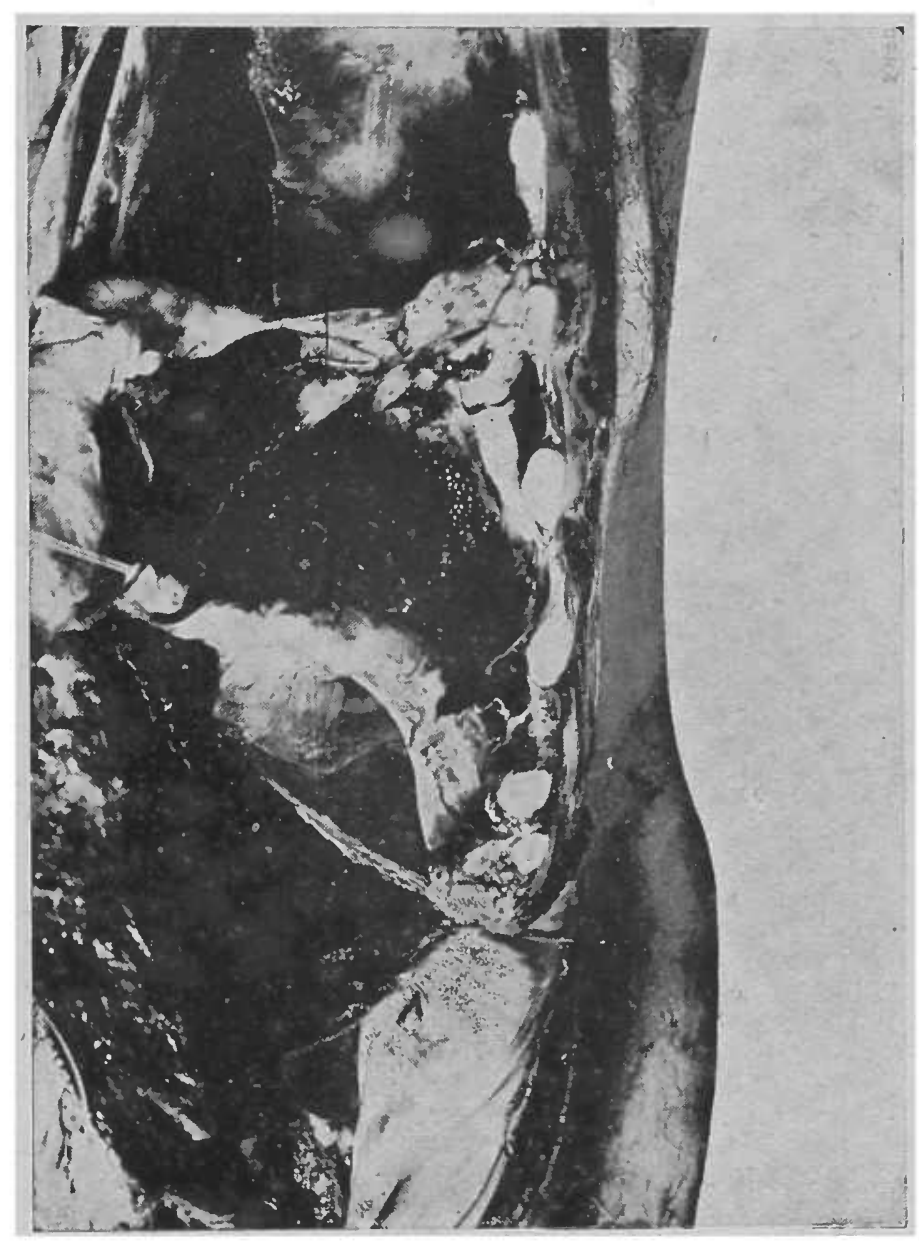

\section{Observação Il}

Debaixo para cima vemos:

a) Porção do aneurisma situada abaixo do diafragma

b) caridade aneurismatica situada entre o plano muscular e a pleura diafragmatica.

c) cavidade pleural esquerda onde existia um derrame sanguineo consequente a rutura do aneurisma nessa cavidade. 
Revista de Medicina

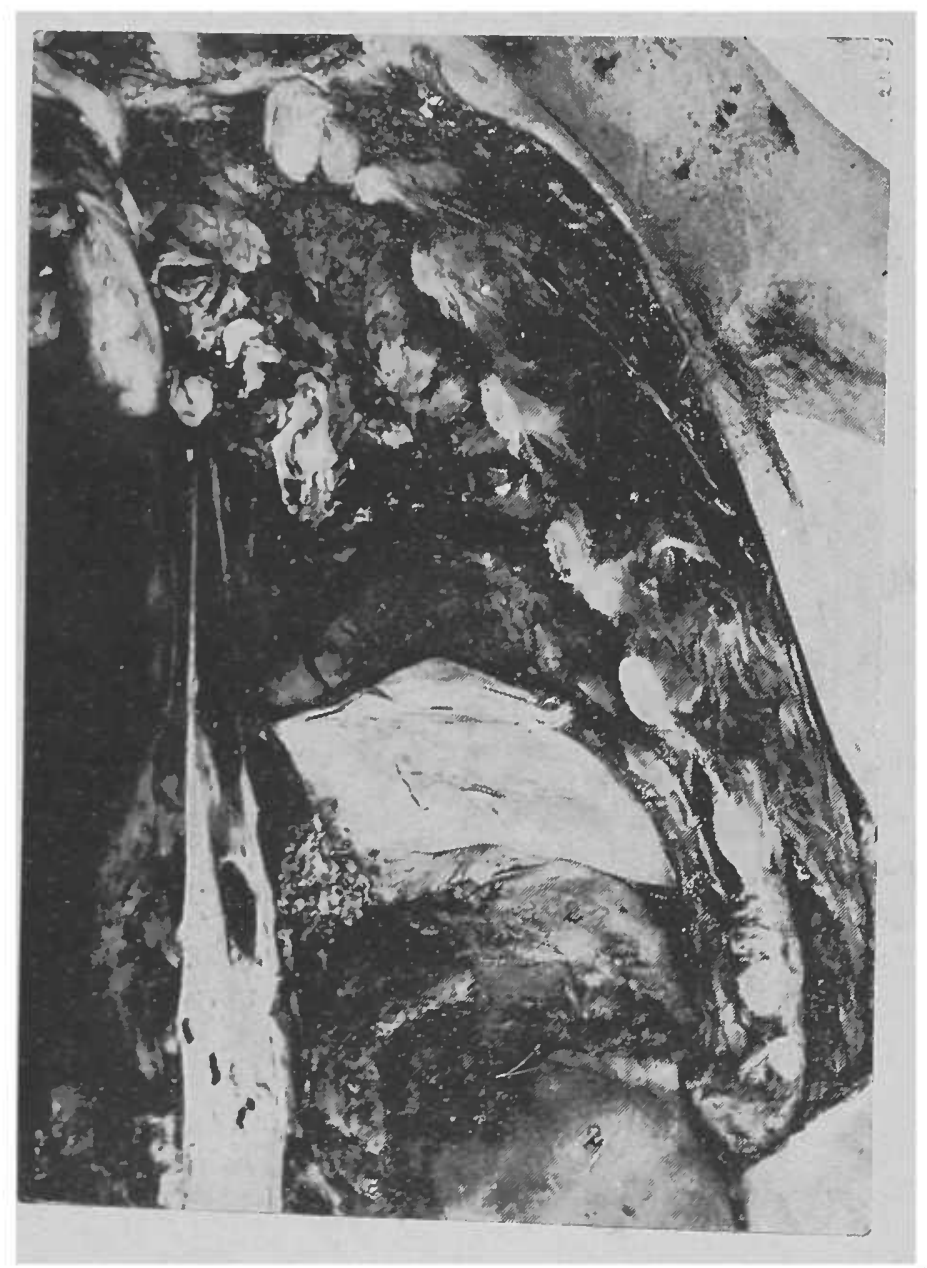

Observação Il 
Cerebro: Leptomeninges finas e transparentes. Vasos da base de aspeto normal. Hemisférios cerebraes simétricos e de consistencia firme. Os cortes frontaes nada mostram de particular.

Rombencefalo: Nada mostra digno de nota.

Orgãos do pescoço: Nada digno de nota.

Cavidade toracica: Area cardiaca recoberta parcialmente pelos pulmóes. Pleura direita livre de aderencias. A cavidade pleural esquerda acha-se ocupada por um grande coagulo sanguineo. A pleura parietal esquerda na base, proemina fortemente para cima e para deniro, for mando um grande abaulamento que comprime o pulmão do mesmo lado para cima e para dentro em direção ao hilo pulmonar. $O$ abaulamento da pleura, na base, é dado por uma massa tumoral que à palpação apresenta consistencia hidrica. Pericardio liso e brilhante, contendo normal quantidade de liquido.

Pulmão direito: Pesa 420 grs. Mede $21 \times 12 \times 6 \mathrm{cms}$. Pleura fina e lisa. A superficie de corte mostra-se de coloração vermelha escura no lobo inferior e roseo palida no superior, tendo disseminado em toda a sua extensão um pontilhado fino e negro.

Pulmão esquerdo. Pesa 320 grs. Mede $14 \times 12 \times 5,5 \mathrm{cms}$. O pulmão esquerdo tem o seu lóbo inferior quasi desaparecido, atelectasico, por compressão exercida através da pleura parietal da base, como já ficou dito mais atraz. Adere fortemente à base deste lobo uma membrana espessada, de superficie lisa, podendo-se entretanto em alguns pontos se separar dela, a pleura visceral do orgão. $O$ aspeto do parenquima pulmonar no lobo superior é esbranquiçado e esponjoso.

Coração: Pesa 280 grs. Mede $9 \times 9 \times 7 \mathrm{cms}$. A superficie externa mostra, na face anterior do ventriculo direito, um espessamento epicardial de forma arredondada, medindo $3 \mathrm{cms}$. de diametro. Cavidades de capacidade normal. Valvulas de aspeto e tamanho normaes. Miocardio mede $5 \mathrm{mms}$. à direitia e $12 \mathrm{mms}$. à esquerda.

Aorta: A endartéria mostra elevações em geral arredondadas, de aspeto perlaceo ou de côr amarela em toda a sua extensão. Em varios pontos a endarteria se apresenta irregular devido a depressões e saliencias que dão à mesma um aspeto rugoso nos referidos pontos.

Cavidade abdominal: Parede abdominal anterior normalmente desenvolvida. Peritonio liso, brilhante e humido. Epiplon pouco gorduroso e retraído. Intestinos ligeiramente distendidos por gazes. Apendice livre de aderencias. Figado ulirapassando $3 \mathrm{cms}$. o rebordo costal do lado direito. Baço recalcado para cima e para diante, situado na face anterior do hipocondrio esquerdo, recobrindo parte do estomago. Estomago deslocado para o hipocondrio direito. O rim e a capsula supra- 
renal esquerdos estão deslocados para diante. $O$ deslocamento para diante do rim esquerdo, capsula supra renal e baço, é devido a presença de uma formação tumoriforme retro-peritoneal, que ocupa - lado esquerdo do abdomen em toda e sua extensão.

Aberta a aorta abdominal pela sua face anterior, verifica-se na face posterior da mesma um orificio de forma oval, de direção longitudinal medindo $3 \mathrm{cms}$. em seu maior diametro; este orificio põe em comunicação a luz da aorta com uma grande cavidade aneudismatica que se extende retroperitonealmente para os Iados; para o lado direito o saco aneurismatico é do tamanho de um ovo de galinha; é limitado anterior e lateralmente por tecido proprio de parede arterial, - qual adere as faces lateraes das vertebras; posteriormente o limite é dado pela face anterior da coluna raquiana, cujas vertebras, como veremos adiante se acham corroídas. Para o lado esquerdo origina-se uma vasta cavidade que ocupa totalmente o lado esquerdo do abdomen, posteriormente ao rim, capsula supra renal esquerda e baço que são deslocados para adiante, em dirreção à parede abdominal anterior. $O$ rim $e$ a capsula supra renal estão separados desta ultima pelo colon descendente e o baço em seus $2 / 3$ externos pelas porçóes anteriores das ultimas costelas. Esta cavidade, cheia por um coagulo em organisação é limitada anteriormente pelas faixas apónevroticas profundas que a separam do rim e do baço. Para dentro é limitada pela face lateral esquerda da coluna raquidiana. Para baixo pela arcada crural; no ponto de saída do nervo crural ella ainda atravessa a arcada aprofundando-se até $2 \mathrm{cms}$. abaixo da espinha iliaca anterior e superior. Posterior e externamente pelas partes moles que delimitam normalmente a parede postero-lateral do abdomen. Superiormente é limitada pelo hemidiafragma esquerdo. Em deteminado ponto a cavidade se continua superiormente atravez do diafragma; atravessa sua parte muscular separando-a da pleura parietal diafragmatica, donde se origina outra cavidade medindo $10 \mathrm{cms}$. de diametro que desloca a pleura diafragmatica para cima empurrando o pulmão esquerdo para cima e para dentro. Nesta cavidade existia um coagulo sanguineo recente. Finalmente na cavidade pleural esquerda um derrame sanguineo, consequente à rutura da face superior desta nova cavidade, correspondente, como já vimos, à pleura parietal esquerda. Retirada a aorta abdominal e o coagulo da cavidade aneurismatica abdominal, verifica-se que as vertebras 12.a dorsal, 1.a $2 .^{a}, 3 .^{a}$ lombares têm anteriormente os seus corpos vertebraes corroidos com conservação dos disguerda, atingindo alem destas a $4 .^{\mathrm{a}}$ e a $5 . .^{\mathrm{a}}$ lombares em menor grau. estão completamente lado esquerdo, assim como o seu ramo sagrado såo forradas por tecido propridos. As paredes do saco aneurismatico não jacentes proprios na região. Ero da artéria e sim pelos tecidos circunjacentes proprios na região. Estas paredes mostram-se irregulares, pela 
destruição mais ou menos intensa dos musculos abdominaes da região dos quaes existem partes apenas; em alguns pontos, na face posterior do abdomen a cavidade aneurismatica é limitada apenas pela pele. É de se notar ainda que as duas ultimas costelas tambem se mostram irregularmente corroídas em toda a sua extensão, sendo que a $12 . .^{2}$ costela, já destacada de sua base, foi retirada livre com o conteúdo do saco aneurismatico.

$\mathrm{Na}$ cavidade peritoneal existem 2 litros de liquido fluido amarelo citrino.

Figado:Pesa 1750 grs. Mede $27 \times 18 \times 9$ cms. Superficie externa lisa. Côr vermelha. Consistencia firme. Superficie de córte mostra nitidamente desenhada e estrutura lobular do orgão. Vesicula piriforme alcança o bordo anterior e contem 10 c.c. de bilis viscosa de côr marron.

Baço: Pesa 200 grs. Mede $15 \times 10 \times 4,5$ cms. Capsula ligeiramente espessada. Côr acinzentada. Consistencia firme. Superficie de córte de côr vermelho vinhósa.

Estomago, duodeno e pancreas: Nada mostram digno de nota.

Rim esquerdo: Pesa 200 grs. Mede $13 \times 7 \times 4$ cms. Superficie externa lisa, nada monstrando digno de nota. Superficie de corte mos tra a cortical ligeiramente espessada; distingue-se bem da medular. Capsula facilmente destacavel.

- Diagnóstico: Hemorragia interna (rutura de aneurisma da aorta abdominal na cavidade pleural esquerda)

Aortite sifilitica e arterioselerose da aorta - Atrofia simples e infiltração gordurosa do miocardio - Atelectasia da base do pulmão esquerdo. Antracose. Sinéquia parcial da pleura da base pulmonar.

Congestão e edema pulmonar - Hiperplasia da polpa vermelha do baço - Congestão passiva e esteatose infiltrativa do figado; ascite. 



\section{Noticiario}

\section{de 1933 \\ Sessões realizadas no decorrer de Março a Junho}

Sessáo ordinaria de 7 de Março de 1933 - Sessão de posse da nova directoria, assim constituida: Presidente - Jayme Rodrigues Secretario Geral - Cassio Portugal Gomes Secretario - Luiz Marino Bechelli

O Dr. Paulo de Almeida Toledo, presidente da ultima directoria, leu o relatorio do que fez em sua gestão, cuja publicidade faremos no proximo numero da revista.

Sessão ordinaria de 21/3/1933 - Presidente - Jayme Rodrigues. Secretario : Luiz Marino Bechelli. Foram apresentados e discutidos os seguintes casos:

Rodrigues.

1) Um caso de Aneurisma Cirsoide da mão - Dtdo. Jayme

2) Consideraçóes Clinicas sobre 2 casos de Aneuryma da Aorta Abdominal - Dtdo. Luiz Marino Bechelli e Acad. Octavio Tisi

Sessão ordinaria de 18/4/1933 - Presidente - Jayme Rodrigues. Secretario - Luiz Marino Bechelli. Foram apresentados os seguintes casos:

1) Sobre um caso de Adenopathia paratracheo-bronchica direita. - Pelo Dito. Salim Aidar.

2) Um caso de Aneurysma da Aorta Abdominal. - Acad. Roberto Placco.

Sessão ordinaria de 27/4/1933 - Presidente - Jayme Rodrigues. Secretario - Luiz M. Bechelli. Foram apresentados e discutidos os seguintes casos:

1) Um caso de Sarcoma Osteoblastico da Extremidade Superior da Tibia. Dtdo. Aldemar Bastos.

2) Um caso de Abcesso Pneumonico Sub-periostal. Dtdo. João Manoel Rossi.

Sessão ordinaria de 16/5/1933 - Presidente - Jayme Rodrigues. Secretario - Luiz M. Bechelli. Foram apresentados e discutidos os seguintes casos:

1) Consideracões sobre um caso com a Syndrome de Morvan. Acad. Paulo da Silva Gordo.

2) Consideraçôes Clinicas sobre um caso de Hemiplegia Espastica. Dtdo. Luiz M. Bechelli.

Além das sessóes acima, o Departamento levou a effeito mais 4 sessøes, em que o Dr. Vicente Baptista, a convite especial, realizou quatro conferencias sobre o estudo das vitaminas $A, B$, e C, estudando as avitaminoses e a evolução do conceito da nutrição. 



\section{ORIENTAÇÕES PARA O USO}

Esta é uma cópia digital de um documento (ou parte dele) que pertence a um dos acervos que fazem parte da Biblioteca Digital de Obras Raras e Especiais da USP. Trata-se de uma referência a um documento original. Neste sentido, procuramos manter a integridade e a autenticidade da fonte, não realizando alterações no ambiente digital - com exceção de ajustes de cor, contraste e definição.

1. Você apenas deve utilizar esta obra para fins não comerciais. Os livros, textos e imagens que publicamos na Biblioteca Digital de Obras Raras e Especiais da USP são de domínio público, no entanto, é proibido o uso comercial das nossas imagens.

2. Atribuição. Quando utilizar este documento em outro contexto, você deve dar crédito ao autor (ou autores), à Biblioteca Digital de Obras Raras e Especiais da USP e ao acervo original, da forma como aparece na ficha catalográfica (metadados) do repositório digital. Pedimos que você não republique este conteúdo na rede mundial de computadores (internet) sem a nossa expressa autorização.

3. Direitos do autor. No Brasil, os direitos do autor são regulados pela Lei n. ${ }^{\circ}$ 9.610, de 19 de Fevereiro de 1998. Os direitos do autor estão também respaldados na Convenção de Berna, de 1971. Sabemos das dificuldades existentes para a verificação se uma obra realmente encontra-se em domínio público. Neste sentido, se você acreditar que algum documento publicado na Biblioteca Digital de Obras Raras e Especiais da USP esteja violando direitos autorais de tradução, versão, exibição, reprodução ou quaisquer outros, solicitamos que nos informe imediatamente (dtsibi@usp.br). 